\title{
Crystal Structures of 3-Hydroxy-6-methylpyrid-2-thione and a Tetrahydrofuran Solvate of Its Disulfide
}

\author{
SVEN FURBERG and BENGT SCHWITTERS
}

\author{
Department of Chemistry, University of Oslo, Oslo 3, Norway
}

The crystal structures of 3-hydroxy-6-methylpyrid-2-thione, and of a tetrahydrofuran solvate of its disulfide, have been derived from counter measurements and refined by least-squares calculations to $R=0.04$. In the thione some evidence is found for an intra. molecular $\mathrm{O}-\mathrm{H}$...S hydrogen bond and neigh. bouring molecules are connected by $\mathrm{N}-\mathrm{H} \cdots \mathrm{S}$ hydrogen bonds. In the disulfide the dihedral angle $\mathrm{C}-\mathrm{S}-\mathrm{S}-\mathrm{C}$ is $96^{\circ}$ and the angles between the pyridine rings and the S,S,C planes are 80 and $15^{\circ}$, respectively. This conformation is stabilized by an intramolecular $\mathrm{O}-\mathrm{H} \cdots \mathrm{N}$ hydrogen bond. The tetrahydrofuran molecule is disordered.

Some of the structural features of the molecules were studied also by CNDO/2 methods.

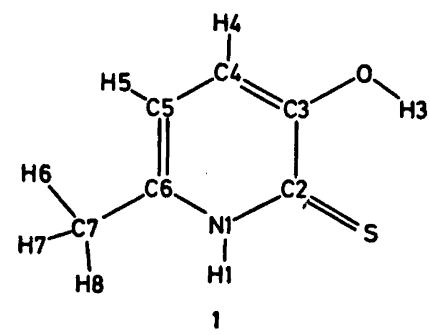

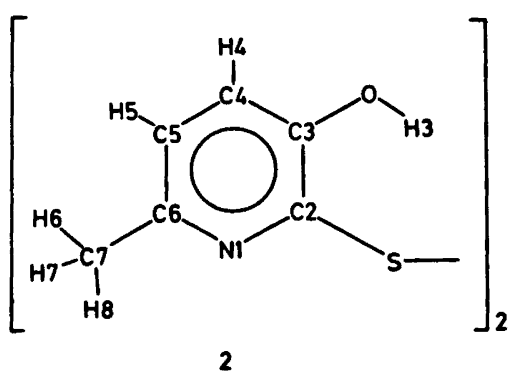

Acta Chem. Scand. B 31 (1977) No. 4
The compound 3-hydroxy-6-methylpyrid-2-thione (1, hereafter called the thione) has imino-, thione- and hydroxyl groups in adjacent positions in the molecule. In connection with earlier crystallographic studies on $N$-heteroaromatics ${ }^{1,2}$ we wanted to examine the struc. ture of this arrangement. Undheim and Lie have studied some of the reactions of the compound. ${ }^{3,4}$ In the Michael additions to $\alpha$-bromocrotonic acids ortho-hydroxyl derivatives, such as the thione, react relatively slowly. This was attributed to hydrogen bonding with 'sulfur. ${ }^{3}$

The thione is readily oxidized to the corre. sponding disulfide (2) and also this compound was investigated.

\section{EXPERIMENTAL}

Needle-shaped crystals of the thione, 'elongated along $a$, were obtained by recrystallization from an 1:1 alcohol-water mixture. Space group and preliminary unit cell dimensions were derived from Weissenberg- and precession photographs and refined by use of diffractom. eter measurements on 15 reflections.

Prismatic crystals of the disulfide were formed by slow evaporation from a tetrahydrofuran (THF) solution. Space group and unit cell dimensions were derived as for the thione, and the latter were refined by diffractometer measurements on 30 reflections.

Densities were measured by flotation. The density for the disulfide indicated that it had crystallized with one-half molecule of THF. The presence of THF in the crystals was confirmed mass spectrometrically.

\section{CRYSTAL DATA}

3-Hydroxy-6-methylpyrid-2-thione, $\mathrm{C}_{6} \mathrm{H}_{7} \mathrm{NOS}$. Space group $P 2_{1} / c$ (No. 14), $a=7.486(4) \AA$, 
$b=11.599(7) \AA, c=15.499(7) \AA, \beta=97.75(4)^{\circ}$, $Z=8, D_{\mathrm{m}}=1.395 \mathrm{~g} \mathrm{~cm}^{-3}, D_{\mathrm{x}}=1.406 \mathrm{~g} \mathrm{~cm}^{-3}$, $\mu(\operatorname{MoK} \alpha)=3.83 \mathrm{~cm}^{-1}$. There are two molecules (called $A$ and $B$ ) in the asymmetric unit.

Bis-3-hydroxy-6-methyl-pyridyl-2,2'-disulfide hemitetrahydrofurane, $\quad \mathrm{C}_{12} \mathrm{H}_{12} \mathrm{~N}_{2} \mathrm{O}_{2} \mathrm{~S}_{8} \cdot \frac{1}{2} \mathrm{C}_{4} \mathrm{H}_{8} \mathrm{O}$. Space group $P 2_{1} / n$ (No. 14), $a=11.724(8) \AA$, $b=13.380(4) \quad \AA, c=9.876(3) \quad \AA, \beta=95.14(3)^{\circ}$, $Z=4, D_{\mathrm{m}}=1.35 \mathrm{~g} \mathrm{~cm}^{-3}, D_{\mathrm{x}}=1.36 \mathrm{~g} \mathrm{~cm}^{-8}$, $\mu(\mathrm{MoK} \alpha)=3.44 \mathrm{~cm}^{-1}$.

\section{DATA COLLECTION}

The intensity measurements on the crystals of the thione and disulfide were, respectively, performed on an automatic Syntex $\mathbf{P} \overrightarrow{\mathbf{l}}$ and Picker diffractometer, using monochromatic MoK$\alpha$ radiation (graphite monochromator) and the $2 \theta-\theta$ scan technique. The thione crystal had dimensions $0.13 \times 0.22 \times 0.83 \mathrm{~mm}$ and was mounted with its needle axis parallel to the $\phi$-axis. 3828 reflections with $2 \theta<65^{\circ}$ were measured, of which 2641 had intensities $I_{0}>$ $2.5 \sigma\left(I_{0}\right)$ and were subsequently used in the refinements. For the disulfide the corresponding data are $0.37 \times 0.40 \times 0.55 \mathrm{~mm}, 3531$ measured reflections with $2 \theta<60^{\circ}$ of which 2917 had $I_{0}>2 \sigma\left(I_{0}\right)$. The intensities of three test reflections did not vary significantly during the data collection. Corrections for absorption and extinction were not applied. This will cause errors in the temperature factors, but not significantly influence the positional param. eters. The atomic form factors were those of Doyle and Turner, ${ }^{5}$ except for hydrogen.

\section{STRUCTURE ANALYSES}

In both structures the positions of the heavy atoms were derived from Patterson and Fourier syntheses. The THF molecules in the disulfide structure must occupy special positions and therefore be disordered. As the individual atoms could not be located on difference maps, the following method was used to derive their positions. Structure factors were calculated for different orientations of a THF molecule of assumed dimensions with $B=5 \AA^{2}$ and with its centre of gravity at $\left(\frac{1}{2}, 0, \frac{1}{2}\right)$. The five ring atoms were all treated as carbon atoms and the THF hydrogen atoms neglected. Two orientations gave minima on an $R$ versus orientation plot. THF molecules were placed in these orientations and tentatively given occupancy values of 0.3 and 0.2 . Their positions were refined by translating the molecules around $\left(\frac{1}{2}, 0, \frac{1}{2}\right)$. The description of the disorder thus obtained can probably be improved by considering more orientations and/or anisotropic thermal movements of the THF molecules.

The hydrogen atoms could not be located in the difference maps and were placed on the basis of stereochemical considerations. One of the methyl hydrogens and the hydroxyl hydrogen were assumed to lie close to the pyridine plane. For the thione the two possible hydroxyl hydrogen positions were tested by least-squares refinements and the position nearest to the sulfur atom gave a reasonable $B$-value, whereas the other gave $B$-values of 30 and $26 \AA^{2}$ for the two independent molecules.

The structures were refined by full-matrix least-squares calculations. The weighting schemes were based on standard deviations from counter statistics and an assumed $2 \%$ fluctuation in diffractometer stability. Anisotropic temperature factors were applied to the ordered non-hydrogen atoms in both structures, isotropic ones to the hydrogen atoms.

It turned out to be necessary to refine the disordered portion of the disulfide structure in order to obtain reasonable parameters for the ordered hydrogen atoms. Positional, thermal (isotropic) and occupancy parameters for the individual atoms of the two THF molecules were therefore included in the least-squares full-matrix calculations. Overlap between atomic positions in the THF molecules caused difficulties during the refinement. In order to achieve convergence stepwise calculations had to be carried out. Some or all of the parameters of the THF molecules were varied, followed by refinement of the ordered portion of the structure, and so on. The hydrogen atoms of the methyl groups would not refine to reasonable positions, and are probably also disordered. In the THF part of the structure the atoms refined to stereochemically unreasonable positions $(\mathrm{C}-\mathrm{C}$ bonds up to $0.2 \AA$ off normal values), indicating that our model of the disorder is not satisfactory. We believe, however, that it is good enough to yield reliable param. eters for the ordered atoms.

Acta Chem. Scand. B 31 (1977) No. 4 
Table 1. Positional and thermal parameters $\left(\times 10^{5}\right)$ for the non-hydrogen atoms in the thione. The temperature factor is $\exp \left[-\left(B 11 h^{2}+B 22 k^{2}+B 33 l^{2}+B 12 h k+B 13 h l+B 23 k l\right)\right]$.

\begin{tabular}{|c|c|c|c|c|c|c|c|c|c|}
\hline & $x$ & $y$ & 2 & 811 & B22 & B33 & 812 & $B 13$ & $B 23$ \\
\hline \multicolumn{10}{|c|}{ Molecule A } \\
\hline$S$ & 37712 (9) & 13784 (4) & -8301 (3) & $3823(17)$ & $828(4)$ & $318(2)$ & $982(14)$ & $-478(8)$ & $-110(4)$ \\
\hline 0 & $34570(22)$ & $38548(12)$ & $-4132(9)$ & $3399(40)$ & $703(11)$ & $440(6)$ & $324(34)$ & $-213(26)$ & $152(14)$ \\
\hline N & $51661(21)$ & $14147(14)$ & $8567(8)$ & $2116(35)$ & $634(12)$ & $327(6)$ & $15(35)$ & $-43(22)$ & $31(14)$ \\
\hline C2 & $44210(24)$ & $20112(14)$ & $1433(10)$ & $1817(38)$ & $683(13)$ & $316(6)$ & $70(39)$ & $120(25)$ & $41(15)$ \\
\hline C3 & $41948(26)$ & $32022(15)$ & $2664(11)$ & $2018(40)$ & $668(13)$ & $368(7)$ & $-104(39)$ & $117(27)$ & $109(16)$ \\
\hline C4 & $46968(31)$ & $36914(19)$ & $10625(12)$ & $2992(55)$ & $670(15)$ & 477 (9) & $-205(49)$ & $30(35)$ & $-129(19)$ \\
\hline C5 & $54325(30)$ & $30121(18)$ & $17634(12)$ & $2839(52)$ & $870(17)$ & $363(8)$ & $-632(50)$ & - $84(33)$ & $-171(19)$ \\
\hline C6 & $56632(25)$ & $18665(16)$ & $16600(10)$ & $1863(40)$ & $831(15)$ & $318(7)$ & $-469(41)$ & $3(26)$ & $39(16)$ \\
\hline C7 & $64230(45)$ & $10427(24)$ & $23605(15)$ & $3095(69)$ & $1031(22)$ & $375(9)$ & $-436(68)$ & $-518(40)$ & $192(22)$ \\
\hline \multicolumn{10}{|c|}{ Molecule B } \\
\hline$S$ & $14478(8)$ & $-2848(4)$ & 12805 (3) & $3208(15)$ & 697 (4) & $396(2)$ & $-109(13)$ & $-505(8)$ & 70 (4) \\
\hline 0 & $17494(24)$ & $12209(16)$ & $27983(8)$ & $3604(44)$ & $1131(15)$ & 307 (5) & $-444(44)$ & $-229(24)$ & $-50(15)$ \\
\hline N & $886(21)$ & $16886(13)$ & $5560(9)$ & $2103(37)$ & $729(12)$ & $301,(6)$ & - $50(34)$ & $42(24)$ & $-60(14)$ \\
\hline C2 & $8189(24)$ & $11163(15)$ & $12770(10)$ & $1767(37)$ & $759(14)$ & $316(6)$ & $-402(38)$ & $101(26)$ & $29(15)$ \\
\hline C3 & $10598(27)$ & $17751(17)$ & $20530(10)$ & $2102(42)$ & $952(17)$ & $309(7)$ & $-584(45)$ & $104(27)$ & $-62(17)$ \\
\hline C4 & $5919(32)$ & $29060(20)$ & $20484(13)$ & $2915(57)$ & $1001(19)$ & $435(9)$ & $-295(54)$ & $397(37)$ & $-382(22)$ \\
\hline C5 & $-1359(32)$ & $34294(19)$ & $12743(13)$ & $2665(54)$ & $805(18)$ & $540(10)$ & $206(50)$ & $472(37)$ & $-154(21)$ \\
\hline C6 & $-4089(25)$ & $28167(17)$ & $5180(11)$ & $1836(40)$ & $778(15)$ & $437(8)$ & $103(41)$ & $297(29)$ & $67(18)$ \\
\hline C7 & $-12039(42)$ & $32768(23)$ & $-3457(16)$ & $2760(62)$ & $922(21)$ & $522(11)$ & $442(62)$ & $120(44)$ & $293(23)$ \\
\hline
\end{tabular}

The final values of the agreement indices are $R=0.040, R_{\mathrm{w}}=0.038$ and $s=2.00$ for the thione, and $R=0.041, R_{\mathrm{w}}=0.039$ and $s=3.45$ for the disulfide. The values of the goodness of fit $(s)$ are slightly large for both structures, especially for the disulfide structure, but this has to be expected in the latter case.

The final parameters are given in Tables 1-4. Lists of observed and calculated structure factors will be supplied by the authors on request.

The calculations were carried out on a CD 3300 and on a CYBER-74 with programs described elsewhere. ${ }^{7,8}$

\section{RESULTS AND DISCUSSION}

The estimated standard deviations derived from the variance-covariance matrix are, as is well known, ${ }^{, 0,10}$ often underestimated in structure analyses. A comparison of the values derived for corresponding bond lengths in molecules $A$ and $B$ in the thione, and residues I and II in the disulfide, indicates that this is the case in the present analyses. The e.s.d.'s given should probably be multiplied by a factor of about two.

The semiempirical theoretical calculations reported in this article have all been done by

Table 2. Positional $\left(\times 10^{4}\right)$ and isotropic thermal parameters for the hydrogen atoms in the thione.

\begin{tabular}{|c|c|c|c|c|c|c|c|c|}
\hline & \multicolumn{4}{|c|}{ Molecule A } & \multicolumn{4}{|c|}{ Molecule B } \\
\hline & $x$ & $y$ & 2 & B & $x$ & $y$ & 2 & B \\
\hline HI & $5285(24)$ & $713(17)$ & $790(11)$ & 3.7 (4) & $-14(26)$ & $1344(16)$ & $124(12)$ & 4.0 (4) \\
\hline $\mathrm{H}_{3}$ & $3291(34)$ & $3401(21)$ & $-820(15)$ & $6.5(6)$ & $1917(31)$ & $564(21)$ & $2645(14)$ & $5.6(6)$ \\
\hline $\mathrm{H}_{4}$ & $4577(28)$ & $4480(20)$ & $1130(13)$ & $5.7(5)$ & $730(30)$ & $3338(19)$ & $2565(14)$ & $6.2(5)$ \\
\hline H5 & $5724(29)$ & $3343(18)$ & $2314(14)$ & $5.7(5)$ & $-492(28)$ & $4191(20)$ & $1243(12)$ & $5.2(5)$ \\
\hline H6 & $6634(41)$ & $1363(25)$ & $2835(21)$ & $8.7(8)$ & $-1635(33)$ & $4031(23)$ & $-287(14)$ & $6.6(6)$ \\
\hline H7 & $7558(47)$ & $693(28)$ & $2279(19)$ & $9.6(9)$ & $-2294(38)$ & $2830(23)$ & $-599(16)$ & $7.7(6)$ \\
\hline H8 & $5701(37)$ & $401(26)$ & $2347(16)$ & $7.7(7)$ & $-351(39)$ & $3266(22)$ & $-730(17)$ & $7.6(7)$ \\
\hline
\end{tabular}

Acta Chem. Scand. B 31 (1977) No. 4 
Table 3. Parameters for the disulfide. Given as in Table 1, except for the coordinates for the tetrahydrofuran atoms (C10-C19) which are multiplied by $10^{4}$. $G$ is the occupancy factor.

\begin{tabular}{|c|c|c|c|c|c|c|c|c|c|c|c|c|c|}
\hline & $x$ & $y$ & \multicolumn{2}{|l|}{2} & \multicolumn{2}{|l|}{ B11 } & \multicolumn{2}{|l|}{ B22 } & B33 & $B 12$ & $B 13$ & \multicolumn{2}{|l|}{ B23 } \\
\hline \multicolumn{14}{|c|}{ Pyridyl I } \\
\hline s & $26250(4)$ & $30243(3)$ & \multicolumn{2}{|c|}{$45742(5)$} & \multicolumn{2}{|c|}{557 (3) } & \multicolumn{2}{|c|}{364 (2) } & $1311(6)$ & $35 \quad(5)$ & $457(7)$ & \multicolumn{2}{|l|}{$44(6)$} \\
\hline 0 & $15326(14)$ & $45255(11)$ & \multicolumn{2}{|c|}{$64632(15)$} & \multicolumn{2}{|c|}{$991(13)$} & & $1428(19)$ & $-474(19)$ & $915(26)$ & \multicolumn{2}{|l|}{$-811(22)$} \\
\hline N & $4667(12)$ & $24084(11)$ & \multicolumn{2}{|c|}{$44276(15)$} & \multicolumn{2}{|c|}{$589(11)$} & \multicolumn{2}{|c|}{$459(8)$} & $1066(17)$ & $-82(15)$ & $323(21)$ & \multicolumn{2}{|l|}{$-104(19)$} \\
\hline C2 & $11806(13)$ & & \multicolumn{2}{|c|}{$48704(16)$} & \multicolumn{2}{|c|}{$559(12)$} & \multicolumn{2}{|c|}{368 (9) } & $872(18)$ & $50(17)$ & $252(23)$ & \multicolumn{2}{|l|}{$128(20)$} \\
\hline C3 & $8420(15)$ & $38294(13$ & 3) 58639( & (18) & 726 & $(14)$ & 4561 & (10) & $969(19)$ & $-32(20)$ & $379(27)$ & $-76(23)$ & \\
\hline C4 & $-2893(18)$ & $38003(16$ & 5) $61723(2$ & 23) & 830 & (17) & 6181 & (13) & $1442(27)$ & $197(24)$ & $747(35)$ & $-353(31)$ & \\
\hline C5 & $-10043(18)$ & $30840(17$ & 7) 56217 (2 & 23) & 573 & $(15)$ & 7601 & 15) & $1602(29)$ & $117(25)$ & $588(33)$ & $-150(34)$ & \\
\hline c6 & $-6136(15)$ & $23862(15$ & 5) 47415( & 20) & 600 & (14) & 6191 & 12) & $1326(24)$ & $-97(21)$ & $330(29)$ & $-173(28)$ & \\
\hline C7 & $-13619(29)$ & 15641132 & 2) 415071 & 48) & 778 & (22) & 12171 & 27) & $2608(67)$ & $-736(39)$ & $790(61)$ & $-1411(73)$ & \\
\hline Pyri & $d y \mid 11$ & & & & & & & & & & & & \\
\hline s & 27899 (4) & 40700 & 3) 31073 & (5) & 842 & (4) & 448 & (3) & $936(5)$ & $-343(5)$ & $451(7)$ & $-177(6)$ & \\
\hline 0 & $37554(12)$ & $57521(10$ & 0) 18592( & 13) & 1022 & $(12)$ & 505 & (8) & $1098(16)$ & $-169(16)$ & $533(22)$ & $159(18)$ & \\
\hline N & $33559(12)$ & $51988(10$ & D) 53355( & 15) & 735 & (12) & 406 & (8) & $1006(17)$ & $-118(16)$ & $167(23)$ & $-75(19)$ & \\
\hline C2 & $33741(13)$ & $51343(12$ & 2) 40007( & 17) & 537 & $(12)$ & 377 & (9) & $1010(20)$ & $-23(16)$ & $235(24)$ & $-31(21)$ & \\
\hline C3 & $38158(14)$ & $58817(12$ & 2) 32160( & (18) & 552 & (12) & 4261 & (10) & $1122(21)$ & $47(18)$ & $293(25)$ & $124(23)$ & \\
\hline C4 & $42805(16)$ & $67023(14$ & 4) 38992( & (22) & 731 & (15) & 4071 & $10)$ & $1458(27)$ & $-195(20)$ & $441(32)$ & $90(26)$ & \\
\hline C5 & $42856(16)$ & $67598(14$ & 4) 52791( & (22) & 732 & (15) & 4161 & (10) & $1428(27)$ & $-228(20)$ & $15(31)$ & $-156(26)$ & \\
\hline C6 & $38135(16)$ & $60069(14$ & 4) 59934( & (19) & 751 & (15) & 4551 & (10) & $1139(21)$ & $-99(20)$ & $19(28)$ & $-182(25)$ & \\
\hline C7 & $37825(30)$ & 60381122 & 2) 74967( & 25) & 1570 & (33) & 6841 & 16) & $1187(27)$ & $-567(40)$ & $285(46)$ & $-416(35)$ & \\
\hline Tet & drofuran & & & & & & & & & & & & \\
\hline & $x$ & y & 2 & G & & 8 & & & $x$ & $y$ & 2 & $G$ & B \\
\hline C 10 & $4604(15)$ & $-740(10)$ & $4095(17)$ & 0.3 & $9(1)$ & 11.51 & (3) & C15 & $5304(12)$ & -691 (9) & $4588(15)$ & $0.16(1)$ & 2.712 \\
\hline CII & $4092(15)$ & $441(12)$ & $5224(16)$ & 0.3 & $4(1)$ & 7.21 & (2) & C16 & $5711(13)$ & $607(13)$ & $4580(15)$ & $0.25(1)$ & 5.513 \\
\hline $\mathrm{C} 12$ & $5420(21)$ & $884(12)$ & $5034(25)$ & 0.3 & $2(1)$ & 10.11 & (5) & $\mathrm{Cl}$ & $4663(11)$ & 948 (8) & $4640(12)$ & $0.30(1)$ & 6.812 \\
\hline $\mathrm{Cl3}$ & $5961(8)$ & $234(11)$ & $4820(11)$ & 0.3 & $2(1)$ & 4.71 & (2) & C18 & $3816(22)$ & $237(24)$ & $4832(27)$ & $0.33(1)$ & $16.0(10$ \\
\hline C14 & $5488(14)$ & $.775(10)$ & $4235(15)$ & 0.4 & $1(1)$ & 9.51 & (4) & Cig & $4216(13)$ & $-625(13)$ & $4897(17)$ & $0.22(1)$ & 4.212 \\
\hline
\end{tabular}

use of the CNDO/2 approximation ${ }^{11}$ with $d$ orbitals on the sulfur atoms. All of the struc. tural parameters involving only non-hydrogen atoms have been taken directly from this work. For bond lengths of the type $\mathbf{X}-\mathbf{H}$ standard values were used.
The thione

The bond lengths and angles are given in Table 5. There are no significant differences in bond lengths between the two independent molecules $\mathrm{A}$ and $\mathrm{B}$, and the discussion will be based on mean values. The rings are essentially planar, but some of the atoms attached to them are significantly displaced. The sulfur atoms

Table 4. Positional $\left(\times 10^{4}\right)$ and isotropic thermal parameters for the hydrogen atoms in the disulfide.

\begin{tabular}{|c|c|c|c|c|c|c|c|c|}
\hline \multicolumn{5}{|c|}{ Pyridyl I } & \multicolumn{4}{|c|}{ Pyridyl II } \\
\hline & $x$ & $y$ & 2 & B & $x$ & $y$ & 2 & B \\
\hline H3 & $2203(21)$ & $4615(17)$ & $6096(23)$ & $5.8(5)$ & $4031(25)$ & $6359(25)$ & $1436(30)$ & $7.9(7)$ \\
\hline H4 & $-513(19)$ & $4268(17)$ & $6772(22)$ & $5.4(5)$ & $4608(18)$ & $7186(17)$ & $3406(21)$ & $4.8(5)$ \\
\hline H5 & $-1751(21)$ & $3048(17)$ & $5842(22)$ & $5.6(5)$ & $4632(17)$ & $7334(16)$ & $5763(19)$ & $4.8 \quad(4)$ \\
\hline H6 & $-1544(34)$ & $1738(31)$ & $3236(47)$ & $10.4(11)$ & $3306(32)$ & $5574(33)$ & $7845(36)$ & $9.9(10)$ \\
\hline H7 & $-2047(40)$ & $1702(28)$ & $4296(39)$ & $10.7(10)$ & $3022(43)$ & $6277(39)$ & $7627(46)$ & $11.2(14)$ \\
\hline H8 & $-1043(44)$ & $1343(39)$ & $3660(54)$ & $14.0(15)$ & $3967(29)$ & $6714(27)$ & $7849(33)$ & $9.0(8)$ \\
\hline
\end{tabular}


Table 5. Bond lengths $(\AA)$ and angles $\left({ }^{\circ}\right)$ for the thione.

\begin{tabular}{|c|c|c|c|c|c|}
\hline & Molecule A & Molecule B & & Molecule A & Molecule B \\
\hline $\begin{array}{l}\mathrm{C} 2-\mathrm{S} \\
\mathrm{C} 2-\mathrm{N} 1 \\
\mathrm{C} 2-\mathrm{C3} \\
\mathrm{C} 3-\mathrm{O} \\
\mathrm{C} 3-\mathrm{C} 4 \\
\mathrm{C} 4-\mathrm{C} 5 \\
\mathrm{C} 5-\mathrm{C} 6 \\
\mathrm{C} 6-\mathrm{N} 1 \\
\mathrm{C} 6-\mathrm{C} 7 \\
\mathrm{~N} 1-\mathrm{H} 1 \\
\mathrm{O}-\mathrm{H3} \\
\mathrm{C} 4-\mathrm{H} 4 \\
\mathrm{C} 5-\mathrm{H} 5 \\
\mathrm{C} 7-\mathrm{H} 6 \\
\mathrm{C} 7-\mathrm{H} 7 \\
\mathrm{C} 7-\mathrm{H} 8\end{array}$ & $\begin{array}{l}1.689(2) \\
1.359(2) \\
1.408(2) \\
1.353(2) \\
1.364(3) \\
1.394(3) \\
1.352(3) \\
1.356(2) \\
1.500(3) \\
\\
0.83(2) \\
0.82(2) \\
0.93(2) \\
0.93(2) \\
0.82(3) \\
0.97(3) \\
0.92(3)\end{array}$ & $\begin{array}{l}1.692(2) \\
1.350(2) \\
1.416(2) \\
1.361(2) \\
1.358(3) \\
1.389(3) \\
1.363(3) \\
1.360(2) \\
1.489(3) \\
\\
0.78(2) \\
0.81(2) \\
0.94(2) \\
0.92(2) \\
0.94(3) \\
1.00(3) \\
0.93(3)\end{array}$ & $\begin{array}{l}\mathrm{S}-\mathrm{C} 2-\mathrm{N} 1 \\
\mathrm{~S}-\mathrm{C} 2-\mathrm{C} 3 \\
\mathrm{~N} 1-\mathrm{C} 2-\mathrm{C} 3 \\
\mathrm{C} 2-\mathrm{C} 3-\mathrm{O} \\
\mathrm{O}-\mathrm{C} 3-\mathrm{C} 4 \\
\mathrm{C} 2-\mathrm{C} 3-\mathrm{C} 4 \\
\mathrm{C} 3-\mathrm{C} 4-\mathrm{C} 5 \\
\mathrm{C} 4-\mathrm{C} 5-\mathrm{C} 6 \\
\mathrm{C} 5-\mathrm{C} 6-\mathrm{C} 7 \\
\mathrm{C} 7-\mathrm{C} 6-\mathrm{N} 1 \\
\mathrm{C} 5-\mathrm{C} 6-\mathrm{N} 1 \\
\mathrm{C} 2-\mathrm{N} 1-\mathrm{C} 6 \\
\mathrm{H} 1-\mathrm{N} 1-\mathrm{C} 2 \\
\mathrm{H} 1-\mathrm{N} 1-\mathrm{C} 6 \\
\mathrm{H} 3-\mathrm{O}-\mathrm{C} 3 \\
\mathrm{H} 4-\mathrm{C} 4-\mathrm{C} 3 \\
\mathrm{H} 4-\mathrm{C} 4-\mathrm{C} 5 \\
\mathrm{H} 5-\mathrm{C} 5-\mathrm{C} 4 \\
\mathrm{H} 5-\mathrm{C} 5-\mathrm{C} 6 \\
\mathrm{H} 6-\mathrm{C} 7-\mathrm{C} 6 \\
\mathrm{H} 7-\mathrm{C} 7-\mathrm{C} 6 \\
\mathrm{H} 8-\mathrm{C} 7-\mathrm{C} 6\end{array}$ & $\begin{array}{l}122.9(1) \\
121.5(1) \\
115.7(1) \\
119.2(2) \\
120.4(2) \\
120.5(2) \\
120.1(2) \\
120.4(2) \\
125.6(2) \\
116.7(2) \\
117.7(2) \\
125.6(2) \\
116(1) \\
118(1) \\
104(2) \\
120(1) \\
120(1) \\
120(1) \\
120(1) \\
112(2) \\
115(2) \\
110(2)\end{array}$ & $\begin{array}{l}123.8(1) \\
120.8(1) \\
115.4(2) \\
117.2(2) \\
121.9(2) \\
120.9(2) \\
119.9(2) \\
120.7(2) \\
125.6(2) \\
117.3(2) \\
117.1(2) \\
125.9(2) \\
116(1) \\
118(1) \\
105(2) \\
121(1) \\
119(1) \\
123(1) \\
117(1) \\
110(1) \\
112(1) \\
110(2)\end{array}$ \\
\hline \multicolumn{3}{|c|}{ Intramolecular hydrogen bond } & \multicolumn{3}{|c|}{ Intermolecular hydrogen bond } \\
\hline $\begin{array}{l}\mathrm{H} 3 \cdots \mathrm{S} \\
\mathrm{O} \cdots \mathrm{S} \\
\mathrm{O}-\mathrm{H} 3 \cdots \mathrm{S} \\
\mathrm{C} 2-\mathrm{S} \cdots \mathrm{H} 3\end{array}$ & $\begin{array}{l}2.37(2) \\
2.960(2) \\
129(2) \\
66(2) \\
\end{array}$ & $\begin{array}{l}2.32(2) \\
2.914(2) \\
131(2) \\
67(2) \\
\end{array}$ & 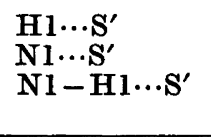 & $\begin{array}{l}2.52(2) \\
3.338(2) \\
168(2)\end{array}$ & $\begin{array}{l}2.60(2) \\
3.346(2) \\
162(2)\end{array}$ \\
\hline
\end{tabular}

are at the largest distance from the planes, 0.043 and $0.039 \AA$ for molecules $A$ and $B$, respectively.

The lengths of the $\mathrm{C}-\mathrm{S}$ and $\mathrm{C}-\mathrm{O}$ bonds, $1.691 \AA$ and $1.357 \AA$, respectively, show that the molecule is the thione/hydroxyl tautomer, as expected. In accordance with other observations on heterocyclic compounds, ${ }^{12}$ the extraannular hydrogen atom attached to the nitrogen atom of the ring causes the $\mathrm{C}-\mathrm{N}-\mathrm{C}$ angle to be rather large.

CNDO calculations on the tautomers 6 methyl-2-mercaptopyridine and 6-methylpyrid2-thione show that the thione form is stabilized relative to the mercapto form. The structures of the tautomers were taken to be similar to the disulfide and the thione, respectively. The calculated dipole moments of the two tautomers differ markedly, being $3.08 \mathrm{D}$ for the mercapto and 7.00 D for the thione form. Jones and Katritzky ${ }^{13}$ have found that in solution the tautomeric forms pyrid-2-thione and pyrid- 4-thione are preferred by factors of $c a \cdot 10^{4,5}$ and $10^{4}$ relative to the mercapto forms.

As far as we know the only other pyridinethione investigated by $\mathrm{X}$-ray methods is $\alpha$ thiopyridone. ${ }^{14}$ This structure is, however, inaccurate $(\sigma \simeq 0.02 \AA)$. The structure most relevant for comparison with the present one would appear to be that of 5-chloro-pyridine-2one..$^{15}$ The bond lengths and angles in the pyridine vary in the same manner in the two compounds. However, the $\chi^{2}$-test ${ }^{16}$ indicates that there are significant differences. It appears that substitution of the sulfur atom by oxygen causes changes in the ring bonds consistent with an increased "contribution" from V.B. structure in formula 1 .

The angles between the $\mathrm{C}-\mathrm{CH}_{3}$ bond and the adjacent ring bonds are strikingly different, as is also found in the disulfide and in 2-carboxy-5-methyl-dihydrothiazolo[3,2-a]. pyridinium-3-carboxylate. ${ }^{17}$ 
The values of the angles between the $\mathrm{C}-\mathrm{O}$ and $\mathrm{C}-\mathrm{S}$ bonds and the adjacent ring bonds indicate an attraction between the hydroxyl and thione groups. The distances $\mathrm{O} \ldots \mathrm{S}$ are 2.960 and $2.914 \AA, H \ldots S 2.37$ and $2.32 \AA$. This indicates the existence of an intramolecular hydrogen bond $\mathrm{O}-\mathrm{H}$...S between the hydroxyl and the thione groups.

CNDO calculations have been performed to roughly estimate the energy of the intramolecular hydrogen bond. A minimum of the energy is found when the hydrogen atom lies in the pyridine plane and points towards the sulfur atom. The calculated energy variation as a function of the dihedral angle $(\phi)$ between the pyridine plane and the plane defined by the atoms $\mathrm{C3}, \mathrm{O}$ and $\mathrm{H}$, keeping other structural parameters constant, can be closely approximated by an empirical function of the Morse potential type plus a cosine term:

$V(\phi)=D\left[1-\exp \left\{-a\left[r(\phi)-r_{\mathrm{e}}\right]\right\}\right]^{2}+\frac{1}{2} V_{2}(1-\cos$

$2 \phi)$ with $r(\phi)=[R-T \cos \phi]^{\ddagger}, r_{\mathrm{e}}=2.310 \AA$,

$R=10.331$ and $T=5.031$.

$D$ is the stabilization energy of the hydrogen bond, while the cosine term approximates the energy variation due to rotation of the hydrox. yl group around the $\mathrm{C}-\mathrm{O}$ bond. A least-squares calculation shows that $D$ is relatively insensitive to the actual values of $a$ and $V_{2}$. With $a=$ $2.5 \AA^{-1} V_{2}$ is $1.8 \mathrm{kcal} / \mathrm{mol}$ and $D=6.6 \mathrm{kcal} /$ mol. This value of $V_{2}$ is comparable with a value of $2.1 \mathrm{kcal} / \mathrm{mol}$ calculated for the compound 3-hydroxy-6-methylpyridine. Charge and $\pi$-bond order as calculated by the CNDO method for the thione are given in Fig. 1.

Intermolecular hydrogen bonds $\mathrm{N}-\mathrm{H} \cdots \mathrm{S}$ link centrosymmetrically related molecules in pairs. The same type of hydrogen bonding is

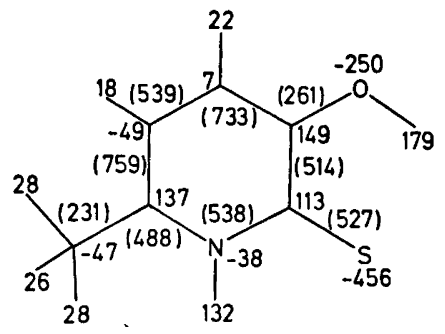

Fig. 1. Charge $\left(\times 10^{3}\right)$ and $\pi$-bond order $\left(\times 10^{3}\right.$, in parenthesis) for the thione.

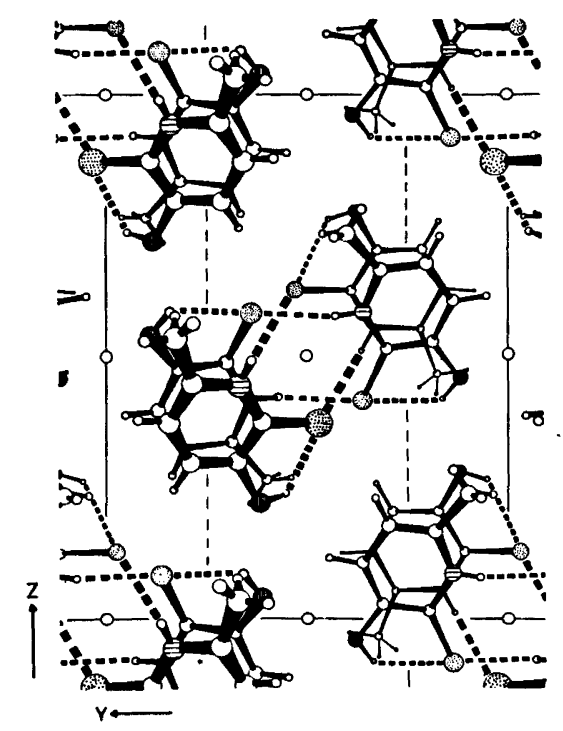

Fig. 2. The a projection of the thione structure. Broken lines indicate hydrogen bonds.

found for the structure of $\alpha$-thiopyridone. ${ }^{14}$ The molecules are nearly parallel to (100) and stack in columns along $a$. Molecules A and B alternate in the columns at distances between molecular planes of about $3.5 \AA$. There is an intercolumn contact of $2.89 \AA$ between the oxygen atoms in molecules $\mathrm{A}$ and $\mathrm{B}$.

The packing arrangement in the thione crystals is shown in Fig. 2.

\section{The disulfide}

Bond lengths and angles are given in Table 6. The two pyridyls are denoted I and II, respectively. The pyridine rings are planar within error limits, but some of the extraannular atoms deviate significantly from the ring planes. The deviations are $(\AA) 0.010,0.047,0.054$ and -0.14 for atoms $\mathrm{S}, \mathrm{O}, \mathrm{C6}$, and $\mathrm{H} 3$, respectively, in pyridyl $\mathrm{I}$, whereas the corresponding distances in pyridyl II are $0.027,-0.031,0.00$ and -0.13 .

The dihedral angle $\mathrm{C}-\mathrm{S}-\mathrm{S}-\mathrm{C}$ is $96.2(1)^{\circ}$, which is within the range of $90 \pm 10^{\circ}$ usually found for organic disulfides. ${ }^{18,19}$ The orientation of the pyridine rings is unusual, as their planes form widely different angles, 14.8 and $79.8^{\circ}$, respectively, with the adjacent S,S,C planes. In the aromatic disulfides so far in-

Acta Chem. Scand. B 31 (1977) No. 4 
Table 6. Bond lengths $(\AA)$ and angles $\left({ }^{\circ}\right)$ for the disulfide.

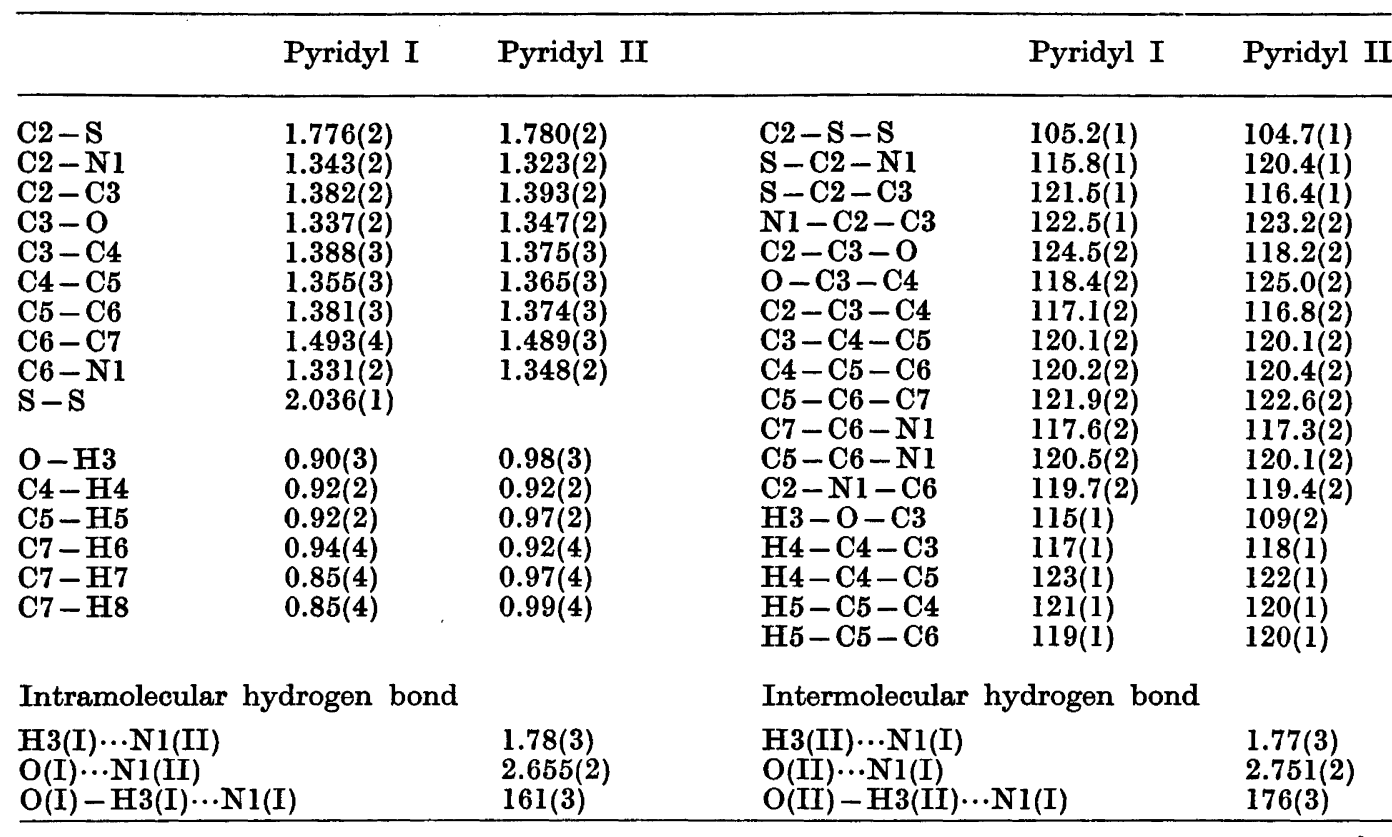

vestigated these angles are approximately equal, being roughly either 0 or $90^{\circ}$. The arrangement found in the present structure is presumably due to the formation of an intramolecular hydrogen bond $\mathrm{O}-\mathrm{H} \cdots \mathrm{N}$ between the two pyridyls.

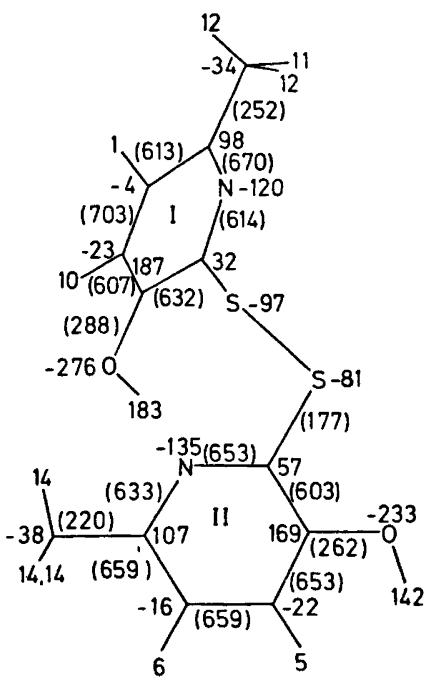

Fig. 3. Charge $\left(\times 10^{3}\right)$ and $\pi$-bond order $\left(\times 10^{3}\right.$, in parenthesis) for the disulfide.
The $\mathrm{S}-\mathrm{S}$ bond is $2.036 \AA$, the $\mathrm{S}-\mathrm{C}$ bonds $1.776 \AA$ and $1.780 \AA$ and the $\mathrm{S}-\mathrm{S}-\mathrm{C}$ angles 105.2 and $104.7^{\circ}$, respectively. In these respects

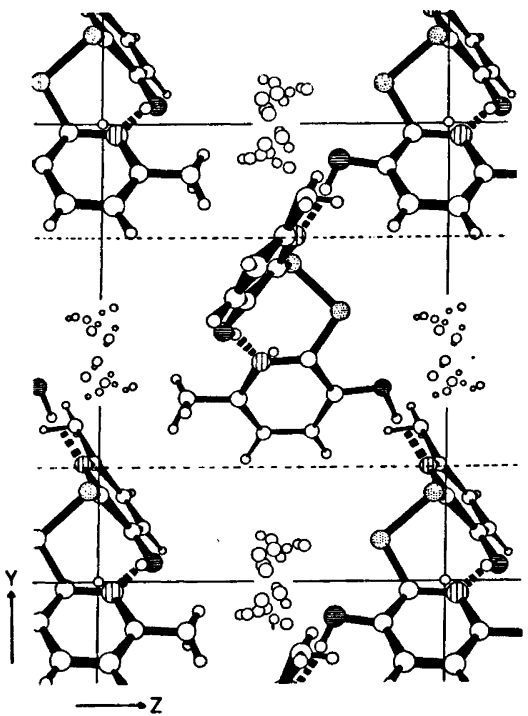

Fig. 4. The $a$ projection of the disulfide. For clarity the mirrorplane-related molecules are not shown. The clusters of small circles indicate atoms in the THF molecules.

Acta Chem. Scand. B 31 (1977) No. 4 
the disulfide belongs to the same type as, e.g., diphenyl disulfide, ${ }^{20}$ in which the angle between the phenyl and the S,S,C planes are 27 and $32^{\circ}$, respectively.

As to be expected, there are significant differences between the thione and the disulfide in the bond lengths and angles of the pyridine ring. The bonds $\mathrm{N} 1-\mathrm{C} 2, \mathrm{~N} 1-\mathrm{C} 6, \mathrm{C} 2-\mathrm{C} 3$ and C4-C5 are shorter in the disulfide, and the bonds $\mathrm{C} 3-\mathrm{C} 4$ and $\mathrm{C} 5-\mathrm{C} 6$ are longer than corresponding ones in the thione, in accordance with the higher degree of delocalization of $\pi$ electrons in the pyridine part of the disulfide.

Charge and $\pi$-bond order in the disulfide calculated by use of the CNDO method are given in Fig. 3.

The disulfide molecules form helices along the screw axes and are connected within the helices by nearly linear $\mathrm{O}-\mathrm{H} \cdots \mathrm{N}$ hydrogen bonds. The THF molecules occupy pockets of diameter roughly $4 \AA$ and are in van der Waals contact with several atoms in surround. ing disulfide molecules. This packing arrangement is shown in Fig. 4.

We wish to thank Professor S. Laland and Dr. K. Undheim for samples of the compounds.

\section{REFERENCES}

1. Furberg, S. and Petersen, C. S. Acta Chem. Scand. 26 (1972) 760.

2. Furberg, S. and Jensen, L. H. Acta Crystal. logr. B 26 (1970) 1260 .

3. Undheim, K. and Lie, R. Acta Chem. Scand. 27 (1973) 1749.

4. Undheim, K. and Lie, R. Acta Chem. Scand. 27 (1973) 1756.

5. Doyle, P. A. and Turner, P. S. Acta Crystallogr. A 24 (1968) 390.

6. Stewart, R. F., Davidson, E. R. and Simpson, W. T. J. Chem. Phys. 42 (1965) 3175.

7. Dahl, T., Gram, F., Groth, P., Klewe, B. and Rømming, C. Acta Chem. Scand. 24 (1970) 2232.

8. Groth, P. Acta Chem. Scand. 27 (1973) 1837.

9. Abrahams, S. C., Hamilton, W. C. and Mathieson, A. McI. Acta Crystallogr. A 26 (1970) 1 .

10. Hamilton, W. C. and Abrahams, S. C. Acta Crystallogr. A 26 (1970) 18.

11. Pople, J. A. and Beveridge, D. L. Approximate Molecular Orbital Theory. McGraw. Hill, New York 1970.

12. Singh, C. Acta Crystallogr. 19 (1965) 861.

13. Jones, R. A. and Katritzky, A. R. J. Chem. Soc. (1958) 3610.
14. Penfold, B. R. Acta Crystallogr. 6 (1953) 707.

15. Kvick, A. and Booles, S. S. Acta Crystallogr. $B 28$ (1972) 3405.

16. Hamilton, W. C. Acta Crystallogr. A 25 (1969) 194.

17. Groth, P. Acta Chem. Scand. 25 (1971) 118.

18. Hordvik, A. Acta Chem. Scand. 20 (1966) 1885.

19. Shefter, E. J. Chem. Soc. B (1970) 903.

20. Lee, J. D. and Bryant, M. W. R. Acta Crystallogr. B 25 (1969) 2094.

Received October 29, 1976. 